\title{
Combined Biological and Advanced Oxidation Treatment Processes for COD and Color Removal of Sewage Water
}

\author{
C. T. Mehmood, A. Batool, and I. A. Qazi
}

\begin{abstract}
Wastewater (WW) generation is inevitable in rapidly growing and urbanizing societies resulting in significant damage to the quality and quantity of fresh water resources. The study was intended to harness the reuse potential of sewage WW using integrated wastewater treatment process. Composite sample of sewage WW was collected from inlet of sewage wastewater treatment plant. The WW sample was batch wise subjected to activated sludge process (ASP), ozonation, UV irradiation, $\mathrm{H}_{2} \mathrm{O}_{2}$ oxidation and sand filtration separately for different time intervals (i.e. 0 to $60 \mathrm{~min}$ ) and concentrations of $\mathrm{H}_{2} \mathrm{O}_{2}\left(0.1\right.$ to $\left.1.0 \mathrm{mlL}^{-1}\right)$, followed by the integration of all the processes at their optimum conditions. Batch experiments were performed in pyrex containers using 1.5L sample except for ASP that is 20L. Efficiencies were measured in terms of COD, color and TSS removal along with changes in $\mathrm{pH}$ and temperature. Biological diversity of $\mathrm{WW}$ was also determined using cultural techniques followed by biochemical tests. Color reduction was much higher and faster than COD in all the tested treatment processes. Ozonation was the fastest process to remove $\mathbf{7 8 \%}$ color in 30 minutes however, ASP was more economical for the same efficiency but requires high hydraulic retention time (HRT). Increase in UV irradiation time reduced COD and color by 54 and $69 \%$ after $60 \mathrm{~min}$ respectively. Sand filter efficiently removed $97 \%$ TSS with marginal reduction in COD. Integration of $4 \mathrm{hr}$ ASP, $24 \mathrm{~min}$ ozonation and $10 \mathrm{~min}$ UV exposure with $1 \mathrm{ml} \mathrm{L}^{-1} \mathrm{H}_{2} \mathrm{O}_{2}$ dose yielded 98 and $100 \%$ COD and Color reduction respectively.
\end{abstract}

Index Terms-Advanced oxidation, COD, color, sewage water.

\section{INTRODUCTION}

Wastewater generation is inevitable in rapidly urbanizing areas like Pakistan having present population of 155 million which is expected to be 229 and 295 millions in year 2025 and 2050 respectively. Estimates suggest that Pakistan had about $5,000 \mathrm{~m}^{3}$ per capita per annum of fresh water in 1951, $1,500 \mathrm{~m}^{3}$ per capita per annum at the moment, and expected to drop less than $1,000 \mathrm{~m}^{3}$ per capita in 2020 to be declared as water stressed country [1]. Furthermore, access to safe drinking water and sanitation facilities are available to only about $65 \%$ and $59 \%$ of total population respectively [2]. It

Manuscript received November 9, 2012; revised 10 January, 2013. This work was supported by the Directorate of Planning and Research, PMAS Arid Agriculture University, Rawalpindi, Pakistan for this project (Project No.AUR/DR-366) Combined Biological and Advanced Oxidation Treatment Processes for COD and Color Removal of Sewage Water.

Ch. Tahir Mehmood and Ishtaiaq A. Qazi are with the Institute of Environmental Sciences of Engineering (IESE), School of Civil and Environmental Engineering (SCEE), National University of Sciences and Technology (NUST), Sector H-12, Islamabad, Pakistan (e-mail: ch.tahir.leo@gmail.com; ishtiaq_qazi@iese.nust.edu.pk).

Aniqa Batool is with PMAS Arid Agriculture University, Rawalpindi, Pakistan (e-mail: aniqabatool@uaar.edu.pk). has been estimated that around 2000 million gallons of sewage is being discharged to surface water bodies daily, while collection level is estimated to be no greater than $50 \%$ nationally (less than $20 \%$ in rural areas), however, only $10 \%$ of collected sewage is effectively being treated [3].

Treatment of wastewater is pricy and difficult due to quality and composition [4]. Many different traditional treatment techniques are being applied on wastewaters such as coagulation/flocculation, membrane separation, ultra filtration, reverse osmosis, microfiltration, activate carbon adsorption and sand filters [4]. However, none of these treatment methods are effective enough to produce water with acceptable levels of the most persistent pollutants (e.g., phenols, pesticides, solvents, household chemicals and drugs, etc.) [5]. Elimination of these compounds by activated carbon produce secondary pollutants, whereas biological treatment is widely used method for removing organic pollutants and some nutrients $(\mathrm{N}$ and $\mathrm{P})$ from domestic effluents however, it is not a complete solution to the problem due to biological resistance of some dyes and inorganic chemicals [4]. Biological methods especially advanced nutrient removal systems are very complicated and difficult to stabilize and optimize especially when a toxic component is involved in the influent. In addition, these processes require a larger construction area and longer time for treatment. Furthermore, disposal of excess biomass is a significant cost component and conventional biological treatments often prove inadequate for complete removal of the pollutants [6].

A further treatment stage is mostly necessary to attain ample removal efficiency. Application of advanced oxidation processes (AOPs) can better serve the purpose as AOPs are recommended when wastewater components have a high chemical stability and/or low biodegradability. A chemical wastewater treatment using AOPs can produce the complete mineralization of pollutants to $\mathrm{CO}_{2}$, water, and inorganic compounds, or at least their transformation into more innocuous products [7].

All the advanced oxidation processes (AOPs) involve the generation of hydroxyl radicals [8].These radicals are very reactive, attack most organic molecules, and are not highly selective [6]. Hence, the advanced oxidation processes (AOPs) like $\mathrm{H}_{2} \mathrm{O}_{2} / \mathrm{UV}$, Fenton, photo-Fenton and photo-catalytic processes could be preferred options to treat and eliminate toxic and hazardous compounds from wastewater. The processes have the capacity to decolorize completely and partially mineralize the wastewater in short reaction time [9]. Fenton and photo-Fenton reactions are fast and efficient; however, they only work in acidic solutions and need extraneous iron (which has to be subsequently 
removed). Photo-catalytic processes also have efficient dye decoloration/degradation capability but the main drawback is the need for a relatively expensive $\mathrm{TiO}_{2}$ catalyst and its subsequent removal [10].

Hydrogen peroxide with UV light has been found to be effective in treating mixed wastewater as it reduces COD, BOD and toxicity of mixed wastewater [11], [12]. Like other AOPs, $\mathrm{H}_{2} \mathrm{O}_{2} / \mathrm{UV}$ process generates hydroxyl radicals and these $\mathrm{OH} \bullet$ radicals (due to their high oxidation potential) change nature of organic molecules either by removing $\mathrm{H}+$ or by adding it to double bonds present in toxic molecules [13]. The photolysis of hydrogen peroxide is preferred over other AOPs due to some advantages such as the complete miscibility of $\mathrm{H}_{2} \mathrm{O}_{2}$ with water, the stability and commercial availability of hydrogen peroxide, no phase transfer problems and lower investment costs [14]-[16]. UV light accelerates the rate of decomposition of $\mathrm{H}_{2} \mathrm{O}_{2}$ with corresponding increase in the rate of $\mathrm{OH} \bullet$ radical formation [12]. Additional advantage is that no residual products are formed and the treatment can be carried out under ambient temperature and the oxygen formed during the process is useful for aerobic biological treatment [6].

The objectives of the study were to investigate the effectiveness of individual WW treatment processes in local conditions and to estimate the effectiveness of integrated wastewater treatment process for improving the wastewater quality for reuse.

\section{MATERIALS AND Methods}

\section{A. Sample Characteristics}

Composite wastewater samples were collected from inlet of sewage treatment plant (STP), I-9 Islamabad. Temperatures of the wastewater samples were measured on site and stored at $4 \mathrm{C}$. Wastewater was characterized using standard methods (Table 1). Biological diversity of WW was determined using cultural techniques followed by biochemical tests.

\section{B. Treatment Processes}

The WW samples were batch wise subjected to activated sludge process (ASP), ozonation, UV irradiation, $\mathrm{H}_{2} \mathrm{O}_{2}$ oxidation and sand filtration separately for different time intervals and concentrations of $\mathrm{H}_{2} \mathrm{O}_{2}$, followed by the integration of all the processes at their optimum conditions. Batch experiments were performed in pyrex containers using 1.5L sample except for ASP, for which 20L sample was used.

Process efficiencies were measured in terms of COD, color and TSS removal along with changes in $\mathrm{pH}$ and temperature. Kinetic degradation of the dissolved organic matter was determined using global parameters like color and COD. Rate constants of decoloration and removal of COD were determined using following exponential relation

$$
\ln \mathrm{C} / \mathrm{C}_{\mathrm{o}}=-\mathrm{k} \mathrm{t}
$$

where $\mathrm{C}$ was concentration of color or COD at time $t, \mathrm{C}_{\mathrm{o}}$ was initial concentration of color or COD, and t time [14].

\section{Statistical Analysis}

The data was analyzed using factorial design and treatment means were compared by LSD using SPSS for Windows version 13.0.

\begin{tabular}{lccc}
\multicolumn{3}{c}{ TABLE I: PHYSIO-CHEMICAL } & CHARACTERISTICS OF WASTEWATER \\
\hline \hline Parameter & Units & Values & WHO Standard \\
\hline COD & $\left(\mathrm{mgL}^{-1}\right)$ & 387 & 150 \\
BOD & $\left(\mathrm{mgL}^{-1}\right)$ & 250 & 100 \\
TSS & $\left(\mathrm{mgL}^{-1}\right)$ & 323 & $<100$ \\
TDS & $\left(\mathrm{mgL}^{-1}\right)$ & 793 & 500 \\
EC & $(\mu \mathrm{S})$ & 1353 & 1000 \\
Temperature & $\left({ }^{\circ} \mathrm{C}\right)$ & 30 & \\
Hardness & $\left(\mathrm{mgL}^{-1}\right)$ & 453 & 500 \\
DO & $\left(\mathrm{mgL}^{-1}\right)$ & 0.23 & 2.0 \\
pH & & 7.53 & $6-8$ \\
Alkalinity & $\left(\mathrm{mgL}^{-1}\right)$ & 520 & 400 \\
\hline \hline
\end{tabular}

\section{RESUlTS AND DisCUSSION}

\section{A. Biological Process}

Activated sludge process was conducted in a plastic container having maximum capacity of 25 liters. Air was supplied using air pump with two outlets via sand stone diffuser placed at the bottom of the reactor. Sludge was prepared before the treatment of actual wastewater sample. Samples were treated for the Hydraulic Retention Time (HRT) of 2, 4, 6, 8 and 10 hours on original $\mathrm{pH}$ and temperature and were not adjusted throughout the treatment process.

Color was reduced faster than COD achieving maximum 73 and $63 \%$ respectively in 10 hrs (Fig. 1). During initial 4 hours of the treatment, color was reduced rapidly (slope $y=14.2$ ) followed by slower rate which is explained by slope $y=2.9$. Similarly COD yielded slope $y=8.78$ in the first 6 hours and the rate was reduced by $77.4 \%$ (i.e. $y=1.98$ ) whereas, strong correlation (0.887) was observed between COD and Color.

High removal efficiencies might be due to the utilization of some readily biodegradable compounds in wastewater by the aerobic microorganism in ASP reactor [17]. COD removal may also be influenced by air stripping caused by the air supply at the bottom of the reactor through spargers [18]. Decrease in color removal rate at HRT above $4 \mathrm{hrs}$ might be due to the formation of colored organic byproducts during the treatment [19].

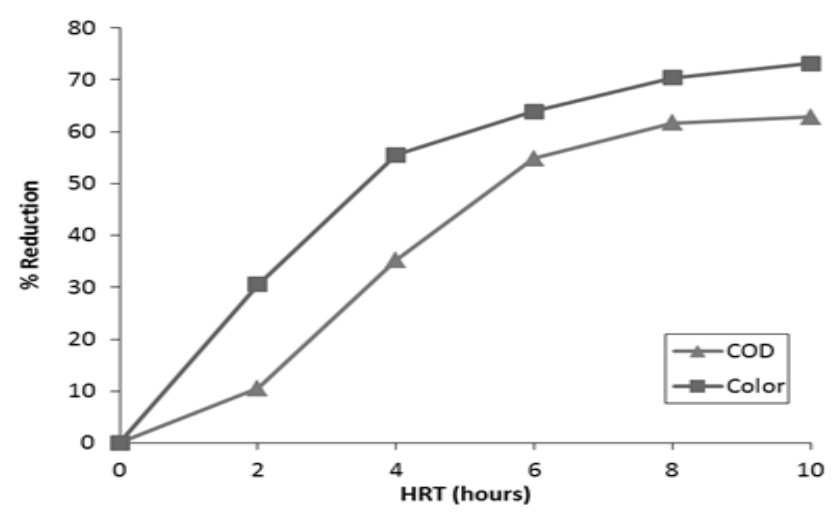

Fig. 1. Effect of HRT on Color and COD removal in ASP 


\section{B. Sand Filter}

Traditional sand filter was prepared using coarse gravel, fine gravel and sand in plastic container having capacity of 5.5 liters. Filling materials (Gravel and sand) were washed with detergents followed by distilled water and air dried. COD, color and TSS removals were statistically significant at $95 \%$ of confidence interval. Over $95 \%$ TSS was removed with $68 \%$ color and $26 \%$ COD reduction (Fig. 2). Removal of TSS with the application of sand filter is basically due to the fine sand particles strongly packed to each other which do not allow the suspended solids to pass through. Color and COD removal is probably due to the interaction of biosand particles and bacterial activity [20].

\section{UV Irradiation}

Ultra violet treatment was carried out as batch experiment at ambient temperature in Photo-reactor comprising of Pyrex cylinder with internal diameter of $10 \mathrm{~cm}$, height of $25 \mathrm{~cm}$ and a total liquid volume of $1.75 \mathrm{~L}$. Ultraviolet lamp had nominal power of $8 \mathrm{~W}(\lambda=254 \mathrm{~nm})$. The UV lamp was positioned in the center of cylinder as a light source.

Analysis of variance (ANOVA) for color and COD with the interaction of varying UV exposure time showed significant decrease in color and COD with increase in UV irradiation time. Maximum color and COD reduction was 76 and $61 \%$ respectively after $120 \mathrm{~min}$ of UV irradiation (Fig. $3)$. Initially color and COD removal rates were faster i.e. $50 \%$ of total color and COD reduction was achieved in just $20 \mathrm{~min}$ and $30 \mathrm{~min}$ respectively. These are depicted by slopes i.e. $\mathrm{y}=1.52$ and 1.09 for color and COD respectively. However, $94 \%$ and $86 \%$ decrease in the rates of color and COD were observed respectively after $50 \mathrm{~min}$. Both color and COD were strongly correlated to UV irradiation time as well as to each other $(\mathrm{r}=0.851)$.

The high intensity of the UV light can change the physicochemical nature of the organic matter in the wastewater. The reduction in the COD and color can be the result of continuous exposure of UV light which provided the energy to the atoms resulting in wide range of chemical reaction. Compounds that absorb UV radiation within the corresponding range of the spectrum may be photo-degraded.

The costs of UV radiation treatment processes depend to a great extent on the absorption properties of the compounds to be eliminated [21]. Real wastewater generally has wide range of chemicals which have the light absorbing potential and are best suited for UV treatment. However, the application of UV light alone is not appropriate to reduce the contaminant contents of wastewater [22].

\section{Ozonation}

Ozonation was carried out in a reactor having similar specifications used for UV experiments. A lab scale ozonator with ozone output of $200-300 \mathrm{mg} / \mathrm{h}$ was used as ozone source. Maximum COD and color reduction was 41.7 and $76 \%$ respectively after $30 \mathrm{~min}$ of ozonation (Fig. 4). Color removal slope $(\mathrm{y}=2.22 \mathrm{x})$ was double as compared to the COD removal slope $(y=1.09 x)$. Ozonation process produces very reactive atomic oxygen which rigorously attaches the organics in the wastewater which ultimately results in the reduction of COD and Color. Further, ozone concentration increases in the air bubbles with increasing time which serves as the driving force for the transfer of ozone to the wastewater with a consequent increase in ozone concentration in the solution and the rate of oxidation [23]. The decolorization of wastewater with increasing time is attributed to the enhancement of mass transfer of ozone from air-ozone bubbles to the liquid phase as a result of the ability of the rising bubbles to induce radial momentum [24] and increase in the gas hold up [25].

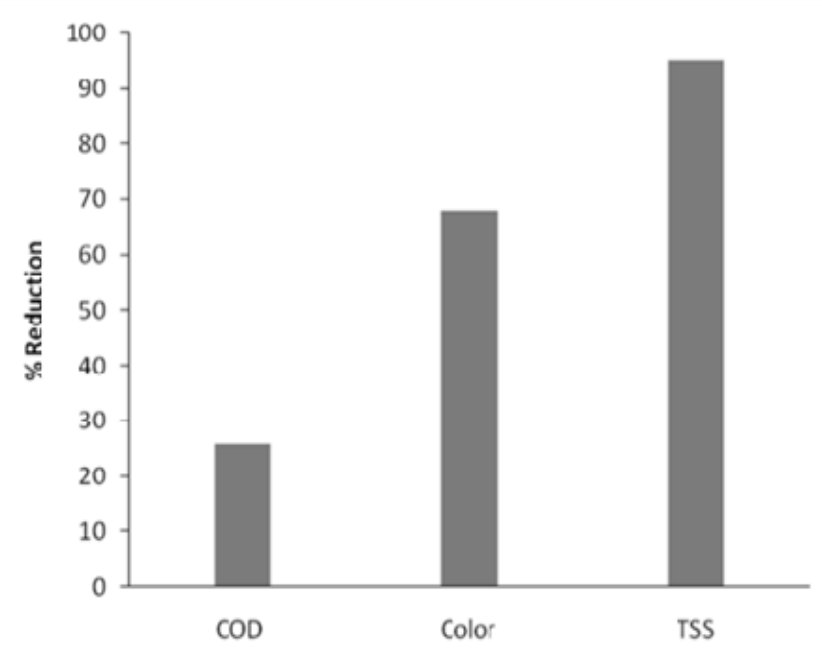

Fig. 2. Reduction in COD, color and TSS of wastewater using sand filter

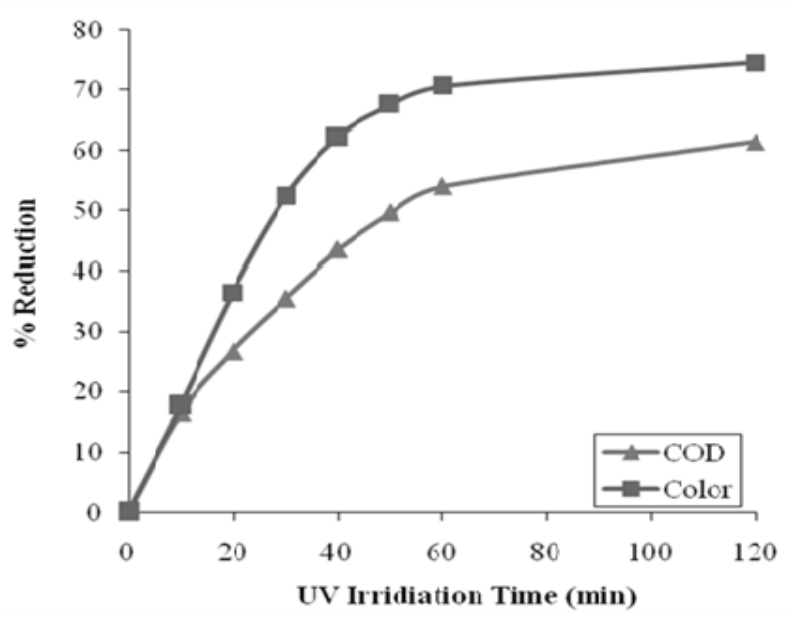

Fig. 3. COD and Color removal of wastewater with increase in UV time

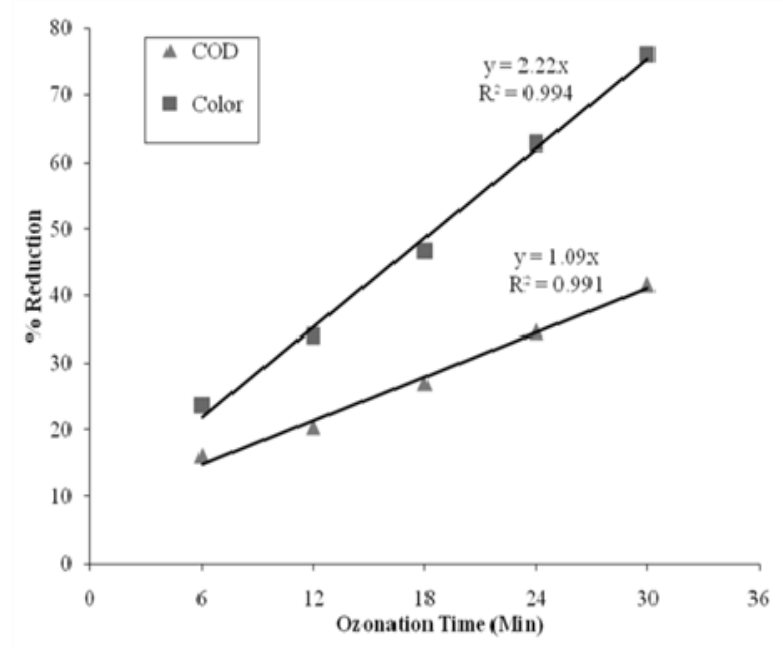

Fig. 4. COD and Color reduction with increase in ozonation time 
Ozonation process was observed as potential option for wastewater treatment [26]. Faster decoloration than the COD reduction during the whole process may be due to the fragmentation of the initial structures of the aromatic colored compounds [3], [6].

\section{E. Hydrogen Peroxide}

Hydrogen peroxide dose was optimized in the pyrex container as described in UV experiment. Stirring was achieved by a rotor placed at the bottom of the reactor. Three levels of $\mathrm{H}_{2} \mathrm{O}_{2}$ (i.e. $0.1,0.5$ and $1.0 \mathrm{ml} / \mathrm{L}$ ) were applied. Hydrogen peroxide application significantly decreased COD and color with increase in $\mathrm{H}_{2} \mathrm{O}_{2}$ concentration from 0.1 to 1.0 $\mathrm{ml} / \mathrm{L}$. Maximum COD and color reduction was 36 and $65 \%$ respectively (Fig. 5). Chemical oxygen demand reduction was more correlated with the hydrogen peroxide dose (i.e $\mathrm{R} 2=0.926)$ than the color removal $(\mathrm{R} 2=0.675)$. Hydrogen peroxide concentration plays a crucial role in deciding the overall efficiency of the degradation process.

It was observed that the percentage degradation of the pollutants increased with an increase in the dose of hydrogen peroxide [27]. The degradation of wastewater may be due to the generation of hydroxyl radicals capable of oxidizing the organic compounds present in the wastewater. Higher doses of $\mathrm{H}_{2} \mathrm{O}_{2}$ produce more number of $\mathrm{OH}$ radicals which degrade the pollutants in the wastewater. Hydrogen peroxide decomposes in one way or another, depending on the type of reaction and the system conditions [28]. Efficiency of $\mathrm{H}_{2} \mathrm{O}_{2}$ decreases with time due to the reasons that, it is consumed gradually and persistent intermediates remain in the system which hinders the performance of the system [26].

\section{F. Integration of Treatment Processes}

Integration of biological process with advanced oxidation processes was also evaluated in terms of COD and Color removal. Biotreated wastewater at optimized HRT (4 hrs) was ozonated for $6,12,18,24$ and 30 minutes followed by UV exposure for 10 to 60 min with three $\mathrm{H}_{2} \mathrm{O}_{2}$ doses $(0.1,0.5$ and $1.0 \mathrm{mg} / \mathrm{L}$ ) separately.

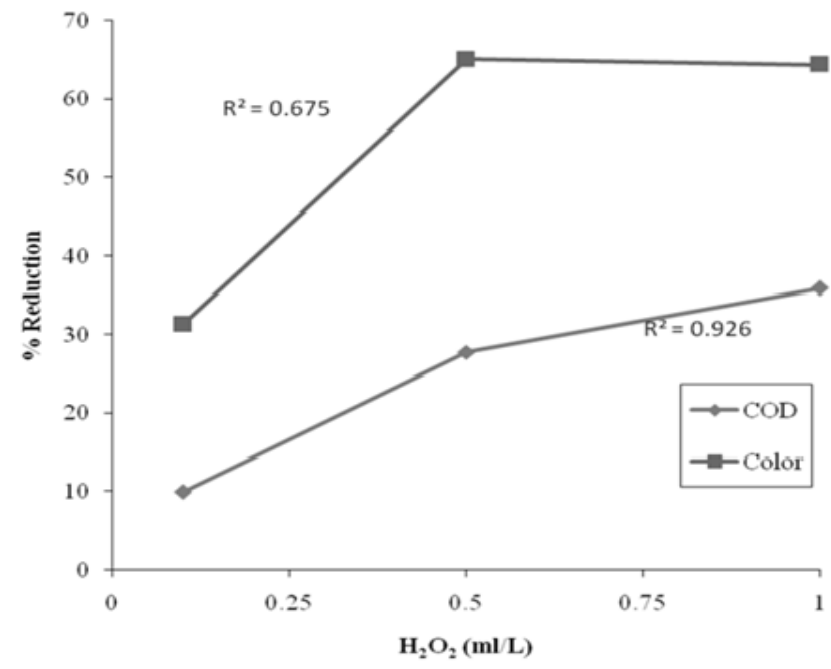

Fig. 5. Reduction in COD and color with different concentration of $\mathrm{H}_{2} \mathrm{O}_{2}$

1) Chemical Oxygen Demand

Maximum COD reduction with interaction of $6 \mathrm{~min}$ ozonation and $60 \mathrm{~min}$ UV exposure in the presence of 0.5 $\mathrm{ml} / \mathrm{L} \mathrm{H}_{2} \mathrm{O}_{2}$ was up to $24.3 \%$ followed by 20.6 and $15.0 \%$ with 1.0 and $0.1 \mathrm{ml} / \mathrm{L} \mathrm{H}_{2} \mathrm{O}_{2}$ dose respectively. Increase in the ozonation time significantly increased the COD reduction while keeping other conditions constant. Chemical oxygen demand decreased faster with 12 min of ozonation along with successive UV doses in the presence of three levels of hydrogen peroxide. The maximum COD reduction was $36.2 \%$ however $21.7 \%$ was achieved in just initial 10 minutes. Increase in ozonation time to 18 minutes, COD reduction jumped to 43,75 and $89 \%$ with $0.1,0.5$ and 1.0 $\mathrm{ml} / \mathrm{L} \mathrm{H}_{2} \mathrm{O}_{2}$ dose respectively after 60 minutes of UV irradiation time. Fastest COD reduction was observed with maximum dose of $\mathrm{H}_{2} \mathrm{O}_{2}(1.0 \mathrm{mg} / \mathrm{L})$.

Most importantly, $54 \%$ COD was reduced in first ten minutes of UV exposure in the presence of $1.0 \mathrm{mg} / \mathrm{L} \mathrm{H}_{2} \mathrm{O}_{2}$ with the rate of $21 \mathrm{mg} / \mathrm{min}$. However, this rate tremendously decreased to $3 \mathrm{mg} / \mathrm{min}$ after first ten minutes of UV exposure. Similar trend was observed in case of $0.5 \mathrm{mg} / \mathrm{L} \mathrm{H}_{2} \mathrm{O}_{2}$ dose but with slightly less rate. Least COD was removed with 0.1 $\mathrm{mg} / \mathrm{L} \mathrm{H}_{2} \mathrm{O}_{2}$ dose at the rate of $3 \mathrm{mg} / \mathrm{min}$.

Further increase in the ozonation time also increased the COD reduction. Maximum 93.4\% COD was reduced with 24 minutes of ozonation, 60 minutes of UV exposure and 1.0 $\mathrm{mg} / \mathrm{L} \mathrm{H}_{2} \mathrm{O}_{2}$ dose.

At 30 minutes of ozonation time followed by the 60 minutes of UV exposure in the presence of $0.5 \mathrm{mg} / \mathrm{L} \mathrm{H}_{2} \mathrm{O}_{2}$ resulted $98 \%$ COD removal (Fig. 6). All the treatment above 18 minutes of ozonation yielded COD within the permissible rage i.e. $150 \mathrm{mg} / \mathrm{L}$.

Increase in $\mathrm{H}_{2} \mathrm{O}_{2}$ dose increase the $\mathrm{OH} \bullet$ radical production causes COD to reduce. Faster reduction in COD during first stage of oxidation was probably due to presence of sufficient amount of hydrogen peroxide which form $\mathrm{OH} \bullet$ radicals and ultimately result in fair reduction of COD as per following equation.

$$
\mathrm{H}_{2} \mathrm{O}_{2}+\mathrm{hv} \rightarrow 2 \mathrm{OH} \bullet
$$

COD reduction is also influenced by $\mathrm{O}_{3}$ and UV irradiation exposure which act as a scavenger of organic material. Decrease in COD removal efficiency could be due to magnesium and calcium salts that crystallize on the quartz sheaths that enclose UV lamps submerged in the wastewater. The resulting scale can reduce the intensity of the light and shield the water from the UV light exposure [29]. This can also be due to increase in temperature that affects $\mathrm{H}_{2} \mathrm{O}_{2}$ solubility in wastewater and decreases the COD removal [30]. Hydrogen peroxide has also scavenging effect on $\mathrm{OH} \bullet$ radicals and persistent compounds require more retention time for complete degradation.

2) Color

High efficiency was observed for color removal with integrated wastewater treatment system. Most of the treatments combination yielded above $90 \%$ color reduction with maximum $99.7 \%$. Low doses of ozonation required longer UV exposure and high oxidation doses of $\mathrm{H}_{2} \mathrm{O}_{2}$ for 
maximum color removal as shown in the Fig. 7.

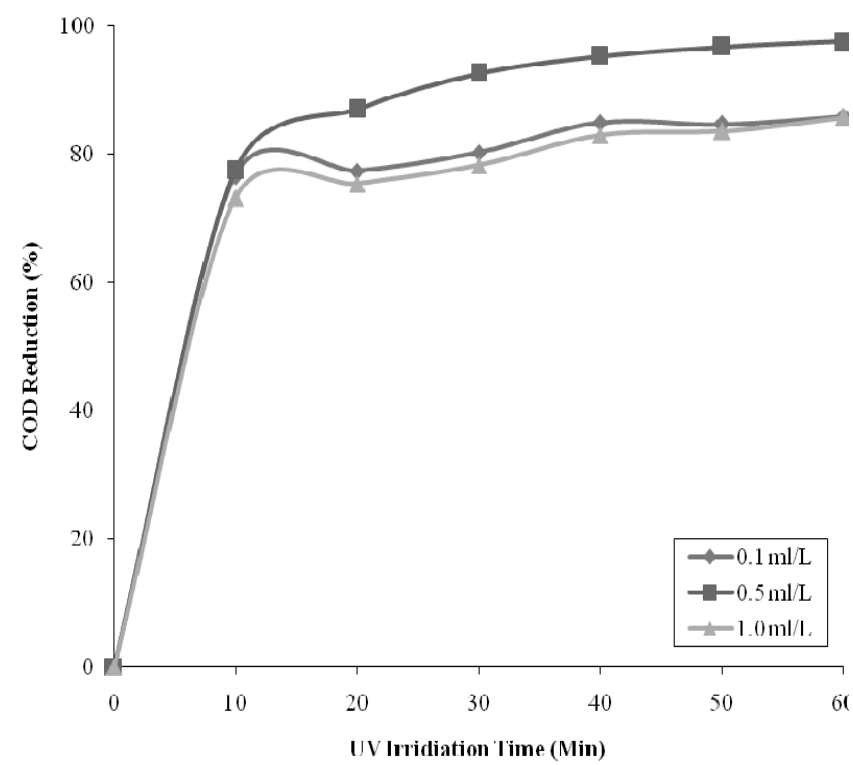

Fig. 6. COD removal of 30 minutes pre ozonated and $4 \mathrm{hr}$ bio treated WW with increase in $\mathrm{UV}$ time and $\mathrm{H}_{2} \mathrm{O}_{2}$ oxidation

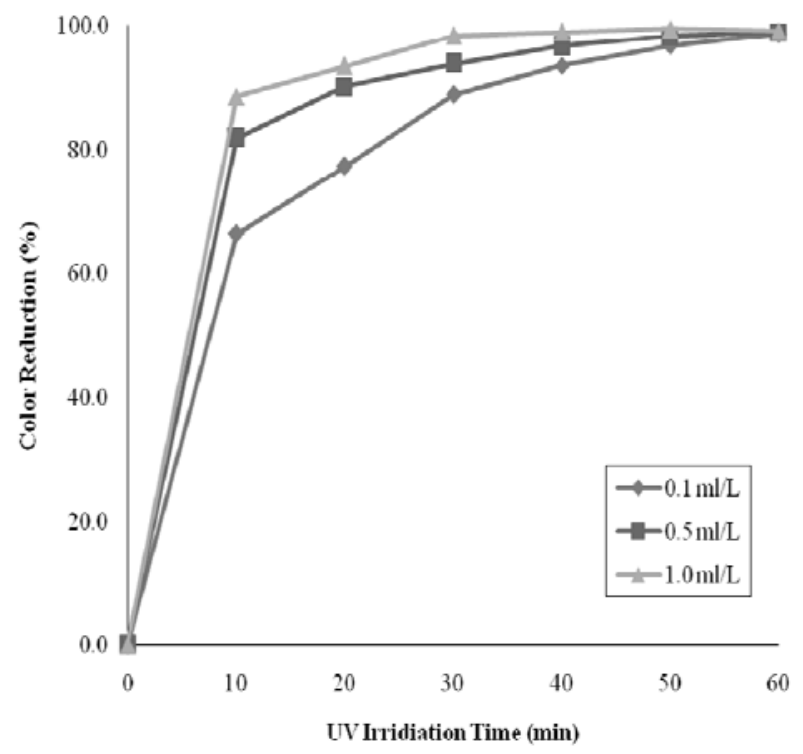

Fig. 7. Color removal of 12 minutes pre ozonated and $4 \mathrm{hr}$ biotreated WW with increase in $\mathrm{UV}$ time and $\mathrm{H}_{2} \mathrm{O}_{2}$ oxidation

Almost hundred percent colors were removed with the application of ozone above 12 minutes with 10 minutes of UV exposure and $\mathrm{H}_{2} \mathrm{O}_{2}$ doses.

Treatment of wastewater had two stages for color reduction. During the startup phase color removal was very high. After ten min color removal was slowed, \% which could be due to the two possible reasons; first that wastewater had readily degradable compounds which require less time to degrade and, secondly, higher energy and time is required to degrade the remaining pollutants in wastewater because they are persistent.

High color removal than COD removal, was probably due to the partial oxidation of unsaturated bonds of chromophoric group responsible for color [31]. However, partially oxidized products contribute to COD because they still demand oxidation until their final degradation occurs [32].
This could also be attributed that $\mathrm{H}_{2} \mathrm{O}_{2}$ solubility decreases at elevated temperature which led to the decrease $\mathrm{OH} \bullet$ radicals and ultimately process efficiency decreased. The efficiency of the integration is higher due the presence of more number of oxidizing species in the system as compared to the individual process [26], [33] and heat produced by UV lamp as well as vigorous mixing of water [34].

\section{CONCLUSION}

The study concluded that different wastewater treatment processes have varying degree of decoloration and COD reduction potential however, the efficiency of the process strongly depends on both the oxidation techniques used and the nature of the pollutants in the wastewater. Integration of AOPs with ASP yielded 98 and $100 \%$ COD and Color removal.

\section{ACKNOWLEDGMENT}

The authors acknowledge financial support provided by Directorate of Planning and Research, PMAS Arid Agriculture University, Rawalpindi, Pakistan for this project (Project No. AUR/DR-366).

\section{REFERENCES}

[1] World Bank, "Pakistan Strategic Country Environmental Assessment," South Asia Environment and Social Development Unit, vol. 1, pp. 51-55, October, 2006.

[2] WHO/UNICEF, Joint Monitoring Programme (JMP) for Water Supply and Sanitation, 2006.

[3] M. S. Rehman, N. Ahmad, A. Yasar, M. Sarwar, and A. Muhammad, "Application of $\mathrm{H}_{2} \mathrm{O}_{2}$, UV and $\mathrm{UV} / \mathrm{H}_{2} \mathrm{O}_{2}$ systems for the treatment of bio treated industrial wastewater," Electronic Journal of Environmental, Agricultural and Food Chemistry, vol. 5, pp. 1575-1582, 2006.

[4] I. Arslan-Alaton, I. A. Balcioglu, and D. W. Bahnemann, "Advanced chemical oxidation of reactive dyes in simulated dye house effluents by ferrioxalate-Fenton/UV-A and $\mathrm{TiO}_{2} / \mathrm{UV}-\mathrm{A}$ processes," Dyes Pigments, vol. 47, pp. 207-218, 2000.

[5] K. L. Walid and Z. Al-Qodah, "Combined advanced oxidation and biological treatment processes for the removal of pesticides from aqueous solutions," Journal of Hazardous Materials, vol. 137, pp. 489-497, February 2006.

[6] M. S. Rehman, A. Khalid, S. Liaquat, C. T. Mehmood, T. Mahmood, and S. Mehmood, "Color and COD removal from poultry litter leachate using an ozonation process," Environmental Engineering and Management Journal, vol. 11, no. 8, pp. 1467-1474, August 2012.

[7] P. Canizares, R. Paz, C. Saez, and M. A. Rodrigo, "Cost of electrochemical oxidation of wastewater: A comparison with ozonation and Fenton oxidation processes," Journal of Environmental Management, vol. 90, pp. 410-420, 2009.

[8] P. Schulte, A. Bayer, F. Kuhu, T. Luy, and M. Volkmer, " $\mathrm{H}_{2} \mathrm{O}_{2} / \mathrm{O}_{3}$, $\mathrm{H}_{2} \mathrm{O}_{2} / \mathrm{UV}$ and $\mathrm{H}_{2} \mathrm{O}_{2} / \mathrm{Fe}^{3+}$ process for the oxidation of hazardous wastes," Ozone Science and Engineering, vol. 17, pp. 119-134, 2009.

[9] M. A. Rauf, S. S. Ashraf, and S. N. Alhadrami, "Photolytic oxidation of Coomassie Brilliant Blue with $\mathrm{H}_{2} \mathrm{O}_{2}$," Dyes and Pigments, vol. 66, pp.197-200, 2005.

[10] H. A. Fatima, M. A. Rauf, and S. Salman Ashraf, "Degradation studies of Rhodamine B in the presence of $\mathrm{H}_{2} \mathrm{O}_{2} / \mathrm{UV}$," Desalination, vol. 239, pp. 159-166, 2009.

[11] K. H. Gregor, "Oxidative decolorization of textile wastewater with AOPs," in Proc. of the 2nd Int. Symp. on Chemical Oxidation Technology for the Nineties. Nashville, TN. USA, pp. 19-21, 1992.

[12] N. H. Ince, "Critical effect of hydrogen peroxide in photochemical dye degradation," Water Research, vol. 33, pp. 1080-1084, 1999.

[13] J. T. Mourand, J. C. Crittenden, D. W. Hand, D. L. Perram, and S. Notthakun, "Regeneration of spent adsorption using homogenous advanced oxidation," Water and Environment Research, vol. 67, pp. 355-363, 1995. 
[14] A. Aleboyeh, M. E. Olya, and H. Aleboyeh, "Electrical energy determination for an azo dye decolorization and mineralization by $\mathrm{H}_{2} \mathrm{O}_{2} / \mathrm{UV}$ advanced oxidation process," Chemical Engineering Journal, vol. 137, pp. 518-524, 2008.

[15] I. Arslan-Alaton and I. A. Balcioglu, "Photochemical and photo catalytic degradation of waste vinylesulphone dyes: a case study with hydrolyzed reactive black5," Journal of Photochemistry and Photobiology, vol. 141, pp. 247-254, 2001.

[16] I. Arslan-Alaton, I. A. Balcioglu, and D. W. Bahnemann, "Advanced oxidation of a reactive dye bath effluent: comparison of $\mathrm{O}_{3}, \mathrm{H}_{2} \mathrm{O}_{2} / \mathrm{UV}$ and $\mathrm{TiO}_{2} / \mathrm{UV}$ processes," Water Research, vol. 36, pp. 1143-1154, 2002.

[17] M. Isik and D. T. Sponza, "Anaerobic/aerobic treatment of a simulated textile wastewater," Separation and Purification Technology, vol. 39, pp. 512-519, 2007.

[18] M. Kornaros and G. Lyberatos, "Biological treatment of wastewater from a dye manufacturing company using a trickling filter," Journal of Hazardous Material, vol. 136, pp. 95-102, 2006.

[19] S. Balku, "Comparison between alternating aerobic-anoxic and conventional actiavated sludge system," Water Research, vol. 41, pp. 2220-2228, 2007.

[20] H. L. Leverenz, G. Tchobanoglous, and J. L. Darb, "Clogging in intermittently dosed sand filters used for wastewater treatment," Water Research, vol. 43, pp. 695-705, 2009.

[21] A. Vogelpohl, "Applications of AOPs in wastewater treatment," Water Science and Technology, vol. 55, pp. 207-211, 2007.

[22] O. Legrini, E. Oliveros, and A. M. Braun, "Photochemical processes for water treatment," Chemical Reviews, vol. 93, pp. 671- 698, 1993.

[23] A. H. Konsowa, M. E. Ossman, Y. Chen, and J. C. Crittenden, "Decolorization of industrial wastewater by ozonation followed by adsorption on activated carbon," Journal of Hazardous Materials, vol. 179, pp. 181-185, 2010.

[24] W. D. Deckwer, "The mechanism of heat transfer in bubble columns reactors," Chemical Engineering and Science, vol. 35, pp. 1341-1346, 1980.

[25] J. S. Groen, R. G. Oldeman, R. F. Mudde, and H. E. Akker, "Coherent structures and axial dispersion in bubble column reactor," Chemical Engineering and Science, vol. 51, pp. 2511-2520, 1996.

[26] P. Canizares, J. Lobato, R. Paz, M. A. Rodrigo, and C. Saez, "Advanced oxidation processes for the treatment of olive-oil mills wastewater," Chemosphere, vol. 67, pp. 832-838, 2007.

[27] S. H. Lin and C. F. Peng, "Treatment of textile wastewater by Fenton's reagent," Journal of Environmental Science and Health, vol. 30, pp. 89-93, 1995.
[28] J. M. Poyatos, M. M. Muñio, M. C. Almecija, J. C. Torres, E. Hontoria, and F. Osorio, "Advanced oxidation processes for wastewater treatment: state of the art," Water Air Soil Pollution vol. 205, pp. 187-204, 2010.

[29] K. H. Wang, Y. H. Hsieh, C. H. Wu, and C. H. Chang, "The pH and anion effects on the heterogeneous photocatalytic degradation of O-methyl benzoic acid in $\mathrm{TiO} 2$ aqueous suspension," Chemosphere, vol. 40, pp. 389-394, 2000

[30] A. Yasar, N. Ahmad, and A. A. Khan, "Energy requirement of ultraviolet and AOPs for the post treated mixed industrial effluents," Coloration Technology, vol. 122, pp. 201-206, 2006.

[31] S. G. Schrank. J. N. Ribeiro, D. S. Souza, and E. E. Santos, "Decolourisation effects of Vat Green 01 textile dye and textile wastewater using $\mathrm{H}_{2} \mathrm{O}_{2} / \mathrm{UV}$ process," Journal of Photochemistry and Photobiology A: Chemistry, vol. 186, pp.125-129, 2007.

[32] W. S. Perkins, S. Law, M. Edward, and C. Smith, "Biological treatability and environmental impact of ozonation of spent reactive dye baths," Textile Chemists and Colorists, vol. 3, pp. 39-43, 2001.

[33] P. K. Malik and S. K. Sanyal, "Kinetics of Decolorization of azo dyes in wastewater by $\mathrm{UV} / \mathrm{H}_{2} \mathrm{O}_{2}$ process," Sep. Purification Technology, vol. 36, pp. 167-175, 2004

[34] T. Mandal, S. Maity, D. Dasgupta, and S. Datta, "Advanced oxidation process and biotreatment: Their roles in combined industrial wastewater treatment," Desalination, vol. 250, pp. 87-94, 2010.

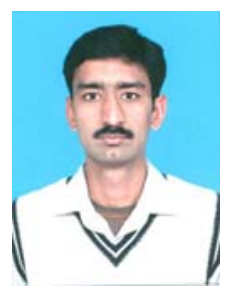

Ch. Tahir Mehmood was born in Mianwali, Pakistan on August 12, 1987. Currently is PhD candidate in the discipline of environmental sciences at Institute Environmental Sciences and Engineering (IESE), School of Civil and Environmental Engineering (SCEE), National University of Sciences and Technology (NUST). M.Phil degree in environmental sciences from PMAS Arid Agriculture University, Rawalpindi, Pakistan was completed in September, 2011. M.Sc degree in environmental sciences from PMAS Arid Agriculture University, Rawalpindi, Pakistan was completed in September, 2009.

$\mathrm{He}$ has worked as intern in the Ministry of Environment for 1 year followed by research assistant in the same ministry renamed as Ministry of Climate Change for 2 years. Recently two papers are published. Now, he is working on combine biological and photo-catalytic degradation of polythene and application of doped $\mathrm{TiO}_{2}$ nanoparticle in the environment.

Mr. Mehmood is member Environmental of Science Society of Pakistan and NUST Environment Club. 